\title{
Os serviços de gestão de recursos hídricos
}

\author{
Water Management Services
}

Guilherme Fernandes Marques ${ }^{1}$ (D), Rosa Maria Formiga-Johnsson² (D), Paula Pedreira de Freitas de Oliveira3 ${ }^{3}$ Carmen Molejon ${ }^{3}$, Cybelle Frazão Costa Braga ${ }^{4}$ (D)

${ }^{1}$ Universidade Federal do Rio Grande do Sul - UFRGS, Porto Alegre, RS, Brasil. E-mail: guilherme.marques@ufrgs.br ${ }^{2}$ Universidade do Estado do Rio de Janeiro - UERJ, Rio de Janeiro, RJ, Brasil. E-mail: formiga.uerj@gmail.com

3Banco Mundial. Brasília, DF, Brasil. E-mails: pfreitas@worldbank.org, carmen.molejon@gmail.com

${ }^{4}$ Instituto Federal da Paraíba - IFPB, João Pessoa, PB, Brasil. E-mail: cybellefcb@gmail.com

Como citar: Marques, G. F., Formiga-Johnsson, R. M., Oliveira, P. P. F., Molejon, C., \& Braga, C. F. C. (2022). Os serviços de gestão de recursos hídricos. Revista de Gestão de Água da América Latina, 19, e1. https://doi.org/10.21168/rega.v19e1

RESUMO: Passados 24 anos da sua promulgação, a Política Nacional de Recursos Hídricos (PNRH) e o Sistema Nacional de Gerenciamento de Recursos Hídricos (SINGREH) comemoram diversos avanços ao marcar a transição para uma abordagem integrada, participativa e descentralizada para a gestão de recursos hídricos. Ao mesmo tempo, os desafios e as demandas crescentes tornaram mais complexo o ambiente de gestão, combinando efeitos do clima, alterações no uso da terra, eventos críticos e sistemas de infraestrutura interligados. 0 presente artigo traz um olhar novo sobre a operacionalização da gestão de recursos hídricos e um conceito inovador ao contexto brasileiro, visando dar unidade e coerência ao que tradicionalmente entendemos como ações ou atividades de gestão. Este conceito explora a gestão de recursos hídricos como um serviço prestado à sociedade, podendo, portanto, ser considerada como serviços de gestão. É um conceito relevante no atual momento brasileiro, no qual arranjos para lacunas diversas de financiamento estão sendo construídos, seja para operação e manutenção de infraestrutura hídrica, seja para o financiamento de ações de gestão em planos de recursos hídricos. 0 artigo apresenta e detalha o conceito e a lógica dos "serviços de gestão" e sua relação com instrumentos diversos e os já conhecidos serviços ecossistêmicos e de saneamento. 0 objetivo é contribuir para que a gestão de recursos hídricos seja entendida a partir de uma estrutura integrada com o intuito de alcançar resultados finalísticos, e não apenas como um conjunto de ações empreendidas por organismos diferentes.

Palavras-chave: Gestão Integrada de Recursos Hídricos; Sustentabilidade Financeira; Governança; Financiamento da Gestão.

ABSTRACT: In 24 years since its promulgation, the Brazilian National Water Resources Policy has advanced significantly in transitioning to a decentralized, participative and integrated water management. In the same period, water challenges have also grown and became more complex, given competitive demands, climate change, and hydrologic variability combined in increasingly interconnected water systems. This paper brings a new view and an innovative concept to the implementation of water management, to build a more coherent reference to what we traditionally understand as water management actions. The paper explores water management as a service delivered to society, hence proposing the concept of water management services. The concept is timely and very relevant in Brazil, as solutions to water management finance gaps are currently under construction, ranging from infrastructure O\&M to other actions and administrative services necessary to execute water resources plans. The paper explains the logic behind the water management services and its relationship with other instruments of the National Water Resources Policy. The main objective is to contribute to a broader understanding of water management as an integrated framework operated to deliver final results to society, rather than a collective of individual actions under responsibility of separated institutions.

Keywords: Integrated Water Resources Management; Finance Sustainability; Water Governance; Water Management Finance.

\section{INTRODUÇÃO}

Passados 24 anos da sua promulgação pela Lei No. 9433/97, a Política Nacional de Recursos Hídricos (PNRH) e o Sistema Nacional de Gerenciamento de Recursos Hídricos (SINGREH)

Recebido: Setembro 24, 2021. Revisado: Dezembro 06, 2021. Aceito: Dezembro 07, 2021. 
comemoram diversos avanços ao marcar a transição para uma abordagem integrada, participativa e descentralizada para a gestão de recursos hídricos no Brasil. Estes avanços colocaram os usuários de água e organizações civis como protagonistas do processo de gestão e estabeleceram uma unidade de referência geográfica para as ações planejadas, na forma da bacia hidrográfica.

Ao mesmo tempo, os desafios e as demandas crescentes por água tornaram mais complexo o ambiente de gestão, combinando efeitos do clima, alterações no uso da terra, eventos críticos mais frequentes e intensos e sistemas de infraestrutura mais elaborados, com objetivos múltiplos e conflitantes, conectando por vezes sistemas hídricos distintos por meio de transposições. As crises hídricas recentes refletem as fragilidades do sistema atual de gestão nesse contexto (Agência Nacional de Águas, 2017a, 2021) e o seu aperfeiçoamento é uma premissa para que as diferentes partes interessadas possam efetivar a gestão descentralizada e as bacias possam ter em seus planos a expressão máxima da pactuação sobre soluções para problemas comuns.

Com o intuito de contribuir para que a PNRH seja mais efetiva em seus objetivos, diversas iniciativas tomaram forma recentemente no Brasil, incluindo análises críticas e propositivas dos 20 anos de implementação da PNRH pela Agência Nacional de Águas e Saneamento Básico (ANA), a exemplo do estudo sobre a governança da água no Brasil da Organização para a Cooperação e Desenvolvimento Econômico (2015), do projeto Legado (Agência Nacional de Águas, 2017b) e do estudo Diálogos para o aperfeiçoamento da Política e do Sistema de Recursos Hídricos no Brasil (Banco Mundial, 2018a, 2018b, 2018c; Braga et al., 2018; Canali et al., 2018; Marques et al., 2018; Medeiros et al., 2018; Persechini et al., 2018).

O projeto Legado incluiu os temas de Segurança e Infraestrutura Hídrica, Modelo de Governança para a Gestão Integrada e os Instrumentos de Gestão de Recursos Hídricos, com recomendações de ajustes em instrumentos legais vigentes para melhorar a representação em organismos de gestão, permitir recortes geográficos diferentes no planejamento, alterar limites para aplicação de recursos e ampliar as possibilidades de se aplicar modelos de pagamento por resultados nas políticas públicas, dentre outras propostas (Agência Nacional de Águas, 2017b). Já o estudo de governança da Organização para a Cooperação e Desenvolvimento Econômico (2015) enfocou duas questões centrais identificadas a partir de um diálogo sobre políticas com a ANA e outras várias partes interessadas: o desempenho do sistema de governança multinível da água (coordenação estadual e federal das políticas e prioridades para os recursos hídricos); e a robustez dos regimes atuais de alocação de água para fazer frente aos diversos riscos futuros associados à mesma (ex: perdas econômicas com escassez, falhas no atendimento a demandas urbanas, comprometimento da geração hidrelétrica e impactos aos ecossistemas, dentre outros).

Uma iniciativa recente, o estudo Diálogos para o aperfeiçoamento da Política e do Sistema de Recursos Hídricos no Brasil (Diálogos), realizado pelo Banco Mundial entre outubro de 2016 e junho de 2018, foi liderado pela Agência Nacional de Águas (ANA) e pela Secretaria de Recursos Hídricos e Qualidade Ambiental (SRHQ). Além da análise temática do Banco Mundial, o estudo "Diálogos" conta com as contribuições da análise de estudos de caso realizada pelo Instituto de Pesquisa Econômica Aplicada (IPEA). Esta iniciativa sistematizou diversos planos, estudos e diagnósticos existentes, reflexões internas da ANA e consultas dirigidas aos atores do SINGREH, com vistas a identificar gargalos e recomendações para a PNRH e seu sistema institucional sob a ótica de cinco temas principais: (i) Modelo de Gestão face às Realidades Hidroclimáticas; (ii) Órgãos Gestores nos Níveis Federal (ANA) e Estadual; (iii) Planos de Recursos Hídricos em Bacias Hidrográficas; (iv) sustentabilidade financeira e (v) Aspectos dos Arcabouços Legal e Institucional.

O aprendizado ao longo do estudo Diálogos proporcionou uma profunda reflexão sobre diversos conceitos referentes à gestão das águas que sejam capazes de contribuir para a resposta aos gargalos identificados. Mais do que uma revisão conceitual, o trabalho mostrou que diversas recomendações propostas precisavam de uma abordagem diferente para serem melhor entendidas e funcionarem como proposto.

0 presente artigo busca consolidar e divulgar parte desse aprendizado, partindo de um olhar novo sobre a operacionalização da gestão de recursos hídricos e trazendo um conceito inovador ao contexto brasileiro, visando dar unidade e coerência ao que tradicionalmente entendemos como ações ou atividades de gestão. Este conceito explora a perspectiva da gestão de recursos hídricos como um serviço prestado à sociedade, podendo, portanto, ser considerado como serviços de gestão. É um conceito relevante no atual momento da gestão de recursos hídricos no Brasil, no qual arranjos para lacunas diversas de financiamento estão sendo construídos, seja para operação e manutenção de infraestrutura hídrica, seja para o financiamento de ações de gestão em planos de recursos hídricos. Uma vez que a gestão envolve a regulação, o uso e o controle das águas de forma interdependente, o conceito de serviços de gestão aqui apresentado é amplo e engloba tanto a parte estrutural associada à infraestrutura quanto a parte nãoestrutural associada ao planejamento e tomada de decisão. A gestão efetiva de recursos hídricos requer que 
ações e decisões nas partes estrutural e não-estrutural sejam integradas, uma vez que ambas a infraestrutura física e a organização institucional/legal/regulatória estão a serviço dos mesmos objetivos elencados na Política Nacional de Recursos Hídricos.

0 artigo apresenta e detalha o conceito e a lógica dos "serviços de gestão" e sua relação com instrumentos de gestão (incluindo aqueles da Lei no 9.433/97) e os já conhecidos serviços ecossistêmicos e de saneamento. 0 objetivo é contribuir para que a gestão de recursos hídricos seja entendida a partir de uma estrutura integrada com o intuito de alcançar resultados finalísticos, e não apenas como um conjunto de ações empreendidas por organismos diferentes. A partir dessa perspectiva, espera-se enfatizar aos gestores, usuários e tomadores de decisão a necessidade de enxergar além dos limites do organismo onde atuam, buscando identificar as lacunas na cadeia de ações e construir relações institucionais necessárias para a sua integração e coordenação. Esta abordagem traz como contribuição, aos trabalhos já existentes na área, uma percepção mais abrangente, integradora e acima de tudo finalística para a gestão de recursos hídricos no país. Por sua vez, esta percepção pode contribuir para um ambiente de planejamento mais receptivo às diversas recomendações propostas em trabalhos como o Legado (Agência Nacional de Águas, 2017b), o estudo de governança da Organização para a Cooperação e Desenvolvimento Econômico (2015) e o estudo Diálogos (Banco Mundial, 2018a, 2018b).

\section{MÉTODOS}

Como este artigo é um dos produtos oriundos do processo de reflexão e discussão conceitual ao longo do estudo Diálogos (Banco Mundial, 2018a, 2018b), a metodologia de sua construção compreende tanto parte da metodologia do próprio estudo Diálogos, descrita a seguir, quanto reflexões complementares dos autores.

A elaboração do trabalho como um todo pelo Banco Mundial envolveu uma fase preparatória para definir o escopo e abordagem metodológica do estudo, identificando os principais temas e estudos de caso a serem analisados. Esta fase envolveu i) revisão bibliográfica de fontes de informação secundária (estudos já realizados, legislação, documentação específica dos temas e estudos de caso); (ii) realização de entrevistas com 39 atores-chave para dar suporte a escolha de temas e estudos de caso; (iii) mapeamento de caraterísticas-chave do universo de estudos de caso; e (iv) análise e processamento de informações para a escolha dos temas.

Como resultado, foram identificados quatro temas de estudo: Tema 1: Modelo de gestão face às realidades hidroclimáticas, Tema 2: Órgãos gestores em níveis federal (ANA) e estadual, Tema 3: Planos de recursos hídricos em bacias hidrográficas e Tema 4: Sustentabilidade financeira. A análise dos quatro temas foi complementada com uma série de questões legais e institucionais associadas aos gargalos identificados na implementação da PNRH e no funcionamento do SINGREH.

A fase seguinte do estudo analisou de forma mais aprofundada cada tema para alcançar conclusões e recomendações específicas. Nesta fase foram entrevistados 72 atores representativos do setor público, usuários de água e sociedade civil, além de oficina temática feita em com participação de 79 atores para validação da versão preliminar dos problemas identificados e as principais recomendações propostas. A metodologia incluiu também a realização de várias reuniões técnicas para discutir avanços e resultados, contando com a participação de colaboradores da ANA, SRHQ, IPEA e Banco Mundial. No total, 263 pessoas do setor foram envolvidas. 0 resultado das discussões gerais e temáticas foi consolidado em uma série de estudos do Banco Mundial (Banco Mundial, 2018a, 2018b, 2018c; Braga et al., 2018; Canali et al., 2018; Marques et al., 2018; Medeiros et al., 2018; Persechini et al., 2018).

A partir destes resultados e aprendizado, a análise do tema sustentabilidade financeira serviu de embasamento para o presente artigo, que avança sobre a estrutura geral de gestão de recursos hídricos para finalmente aprofundar e detalhar o conceito de serviços de gestão de recursos hídricos aqui discutido.

\section{RESULTADOS E DISCUSSÃo}

\section{Governança dos Recursos Hídricos e Lacunas de Financiamento para a Gestão Integrada}

Reflexões recentes sobre a adoção da Gestão Integrada de Recursos Hídricos (GIRH) apontam para a necessidade de mudanças na forma como a comunidade envolvida conduz as estratégias e especialmente como realiza investimentos (Rees et al., 2008; World Water Council, 2015). Dentre os diversos gargalos já apontados para a gestão de recursos hídricos no Brasil e no mundo (Organização para a Cooperação e Desenvolvimento Econômico, 2012, 2015, 2017; Banco Mundial, 2018a, 2018b; 
Hanak et al., 2014; Mehta \& Canal, 2004), a sustentabilidade financeira é um ponto recorrente, cujas demandas pedem uma reforma significativa na estrutura de governança da água, abandonando a tomada de decisão fragmentada e construindo um ambiente onde as relações políticas, comerciais e até os próprios riscos sejam mais bem compreendidos (Rees et al., 2008).

Diversos trabalhos trouxeram contribuições relevantes para solucionar a questão do financiamento de ações, programas e planos associados aos recursos hídricos e à sua governança (incluindo o saneamento), com destaque para o trabalho pioneiro de Winpenny (2003), também conhecido como Relatório Camdessus, que estudou o problema de financiamento de infraestrutura de abastecimento de água e saneamento para alcance dos objetivos do milênio (SDG). Winpenny (2003) verificou que fluxo de recursos financeiros necessários para atingir os objetivos do Milênio no período 2002-2025 (irrigação, efluentes industriais e domésticos, gestão de recursos hídricos e ambiental) deveria ser o dobro do empregado em 2003 (o que implicaria em um aumento de 75 para 180 bilhões de US\$ de investimentos no período). Na mesma linha, Gurria (2006) explorou os desdobramentos das demandas por investimentos, com maior enfoque ao atendimento às demandas hídricas, especialmente envolvendo ações para desenvolver competências institucionais e financeiras em nível local de modo a ampliar a sua capacidade em absorver maior aporte de recursos financeiros.

Contudo, um ponto em comum nesses trabalhos foi o enfoque dado às questões de financiamento pelo lado do aumento na oferta de recursos financeiros para a gestão: como ampliar a disponibilidade de recursos das fontes disponíveis e obter novas fontes de recursos para financiar serviços específicos, especialmente envolvendo abastecimento de água, saneamento e infraestrutura, bem como à arquitetura financeira necessária para o seu funcionamento. Esta visão tão restrita do setor de recursos hídricos foi destacada em Rees et al. (2008) ao observar que a questão do financiamento da estrutura de gestão de recursos hídricos e seu sistema de governança permaneciam omitidas. Essa estrutura de gestão tem um escopo mais amplo, incluindo, por exemplo, o arranjo institucional para regulação de usos, deliberações e tomada de decisões, coleta e organização de dados e elaboração de planos e estudos específicos. Trabalhos mais recentes, a exemplo de Organização para a Cooperação e Desenvolvimento Econômico (2012), com a estrutura de princípios para sustentabilidade financeira, e World Water Council (2015), com o conceito "3T" (taxas, tarifas e transferências), ampliam essa percepção. Entretanto, ainda permanece a questão crítica envolvendo a sustentabilidade financeira dos processos de gestão para assegurar que todo o setor hídrico funcione de forma eficiente.

Rees et al. (2008) buscaram explorar conceitos para o entendimento sobre o financiamento da gestão de recursos hídricos, fazendo uma distinção entre os serviços finalísticos aos usuários (denominados de water services) e o escopo daquilo que chamaram de "funções de governança e gestão de recursos hídricos" necessárias para a provisão dos serviços finalísticos. Estas últimas incluem tanto a construção e manutenção de infraestrutura física quanto o desenvolvimento técnicoinstitucional necessário para a integração de todo o sistema, envolvendo coleta de dados, análise de sistemas, planejamento e engajamento de usuários (Quadro 1).

Os elementos do lado esquerdo do Quadro 1 (funções de governança e gestão) são organizados tanto para prover a disponibilidade de água necessária, em quantidade e qualidade, ao desenvolvimento socioeconômico e à proteção dos ecossistemas, quanto para a mitigação e adaptação aos impactos das externalidades e desastres naturais.

É possível perceber que existe uma relação de dependência entre as diferentes funções de governança, o que requer a sua integração para que sejam alcançados os resultados ao usuário (lado direito do Quadro 1). Entretanto, as fontes e lógicas de financiamento para essas funções são quase sempre dissociadas, envolvendo tanto o setor de recursos hídricos quanto outros setores econômicos (Matheiß et al., 2010). Por exemplo, ao assegurar recursos para obras de infraestrutura hídrica (dentro da função "Proteção, recuperação e desenvolvimento de recursos hídricos"), o planejador nem sempre enxerga se as capacidades institucional, de planejamento, coordenação e engajamento das partes interessadas (dentro das funções "Estratégia, planejamento e elaboração de políticas hídricas" e "Engajamento das partes interessadas") são suficientes para determinar a distribuição dos benefícios e custos da obra (especialmente para a sua operação durante a vida útil). No caso do Brasil, um exemplo emblemático desta dissonância é o Projeto de Integração do Rio São Francisco (PISF) cujo investimento de $11 \mathrm{R}$ \$ bilhões em 17 anos ainda carece de um arranjo legal, comercial e financeiro para viabilizar a operação e manutenção do projeto (Kelman, 2020). Sem essa solução, como aponta o autor, o investimento corre o risco de se perder por danos resultantes da falta de manutenção ou ainda por limitações em sua operação para atender plenamente aos usos previstos. As consequências são o comprometimento dos serviços finalísticos aos usuários, apresentados ao lado direito do diagrama da Figura 1. 
Quadro 1 - 0 sistema de Governança e gestão de recursos hídricos

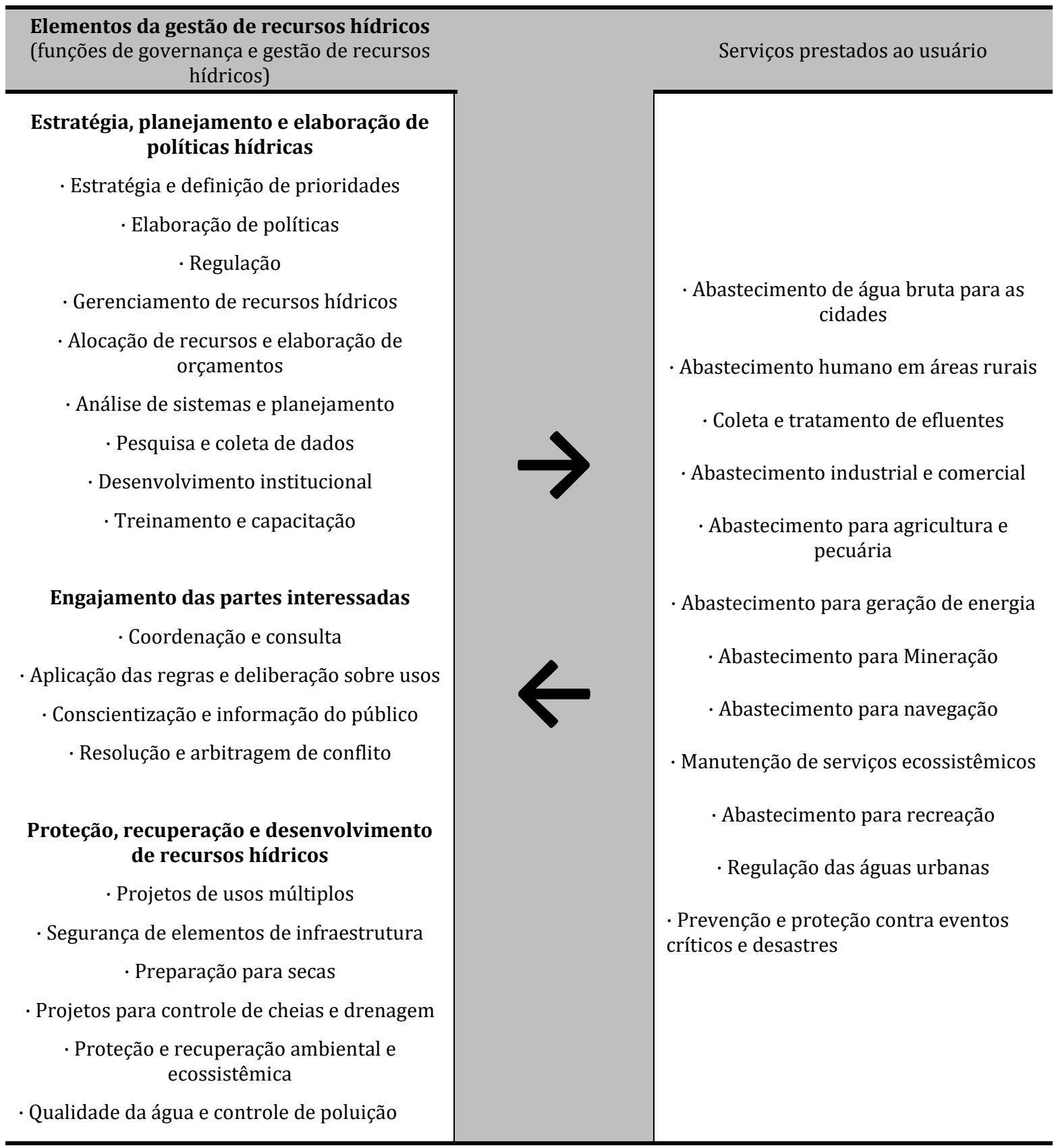

Adaptado de Rees et al. (2008)

Para Rees et al. (2008), os resultados finalísticos aos usuários somente serão providos ao se estabelecer uma conexão fundamental entre investimentos em infraestrutura hídrica e investimentos na capacidade institucional, de formulação de políticas e de práticas de gestão. De modo análogo, a falta de uma lógica integrada para o estabelecimento da conexão entre as diferentes ações impede a exploração efetiva das diversas fontes de financiamento (muitas das quais fora da governabilidade do setor de recursos hídricos). Este gargalo torna bastante limitado o planejamento financeiro para a estrutura de gestão dos recursos hídricos, quando existente. A exemplo do que é verificado no Brasil, são efetivamente lacunas de sustentabilidade financeira que terminam por comprometer a efetividade da gestão como um todo. 


\section{O que são Serviços de Gestão, quem presta estes serviços e como são pagos}

Ao longo do seu desenvolvimento, o estudo Diálogos (Banco Mundial, 2018a) chegou à mesma conclusão que Rees et al. (2008): a solução para o gargalo de sustentabilidade financeira da gestão de recursos hídricos no Brasil depende da adoção de uma visão integradora da estrutura de governança e ações empreendidas, com o seus respectivos custos e relações de dependência. 0 conceito dos serviços de gestão surgiu dessa percepção no estudo Diálogos, com o objetivo de consolidar e dar concretude a essa visão integradora.

Como definido por Lanna (1999, p. 5), a gestão dos recursos hídricos no Brasil é tradicionalmente vista como uma atividade voltada para a:

“formulação de princípios e diretrizes, ao preparo de documentos orientadores e normativos, à estruturação de sistemas gerenciais e à tomada de decisões que têm por objetivo final promover o inventário, uso, controle e proteção dos recursos hídricos".

Nesse contexto, o termo "gestão de recursos hídricos" por vezes torna-se elusivo. Se um conjunto de organismos do SINGREH (órgão gestores, executivos ou colegiados) ou até fora dele (municípios, empresas de saneamento, secretarias de governo) implementa ações que fazem parte da gestão, com níveis diferentes de resultados, como saber se estamos de fato gerindo bem a água? Como garantir os resultados finalísticos da gestão em uma rede de atribuições e responsabilidades longa e diversa, onde uma ação depende dos resultados de outra para ser efetiva?

Para responder essas perguntas, observamos inicialmente que as finalidades da gestão remetem aos objetivos na Política Nacional de Recursos Hídricos, a saber: assegurar a disponibilidade de água às gerações atuais e futuras; fazer o uso racional dos recursos hídricos para o desenvolvimento sustentável; a prevenção e defesa contra eventos críticos e o incentivo à captação, preservação e aproveitamento de águas pluviais. Os termos em negrito denotam um elemento em comum: a sociedade para a qual todo o aparato de gestão é posto em funcionamento, incluindo os usuários. Embora o termo "usuário" seja comumente associado àqueles que captam água diretamente nos mananciais, cabe destacar que toda a sociedade é composta por usuários que, direta ou indiretamente, necessitam tanto de água quanto da prevenção e defesa contra eventos críticos proporcionada pelo aparato de gestão e sua estrutura de governança.

Ao buscar disponibilizar a água bruta, desenvolver sistemas produtivos, promover o desenvolvimento sustentável e proteger a sociedade contra eventos críticos, as conhecidas funções de gestão e governança de recursos hídricos, elencadas por Rees et al. (2008) no Quadro 1, podem também ser entendidas como serviços prestados aos cidadãos e aos interesses difusos: são os serviços de gestão. A Figura 1 apresenta um detalhamento do que são os serviços de gestão propostos neste artigo, organizados em três grandes grupos:

(a) Formulação de estratégias, planejamento e elaboração de políticas hídricas. Exemplos de serviços dentro deste grupo incluem estratégia e definição de prioridades; elaboração de políticas, regulação, alocação de recursos e elaboração de orçamentos, análise de sistemas e planejamento, pesquisa e coleta de dados, desenvolvimento institucional, treinamento e capacitação.

(b) Engajamento das partes interessadas. Exemplos de serviços dentro deste grupo incluem coordenação e consulta, aplicação das regras e deliberação sobre usos, conscientização e informação do público e resolução e arbitragem de conflito.

(c) Proteção, recuperação e desenvolvimento de recursos hídricos. Exemplos de serviços dentro deste grupo incluem projetos de usos múltiplos, segurança de elementos de infraestrutura, preparação para secas, controle de cheias e drenagem, proteção e recuperação ambiental e ecossistêmica, qualidade da água e controle de poluição.

A organização em grupos tem apenas efeito didático. Na medida em que as diversas ações em todos os grupos dependem umas das outras, os serviços de gestão só existem mediante a integração entre os grupos com foco nos resultados finalísticos à sociedade (lado direito na Figura 1). Por exemplo, a segurança e uso efetivo da infraestrutura hídrica (grupo c) depende não apenas da sua operação e manutenção, mas sobretudo da estrutura de governança necessária para regular os usos na sua área de influência e coletar e fornecer informação hidrometeorológica e de previsão para a operação (grupo a) além da negociação e pactuação com usuários sobre qual o conjunto ideal de regras operativas a adotar (grupo b). 


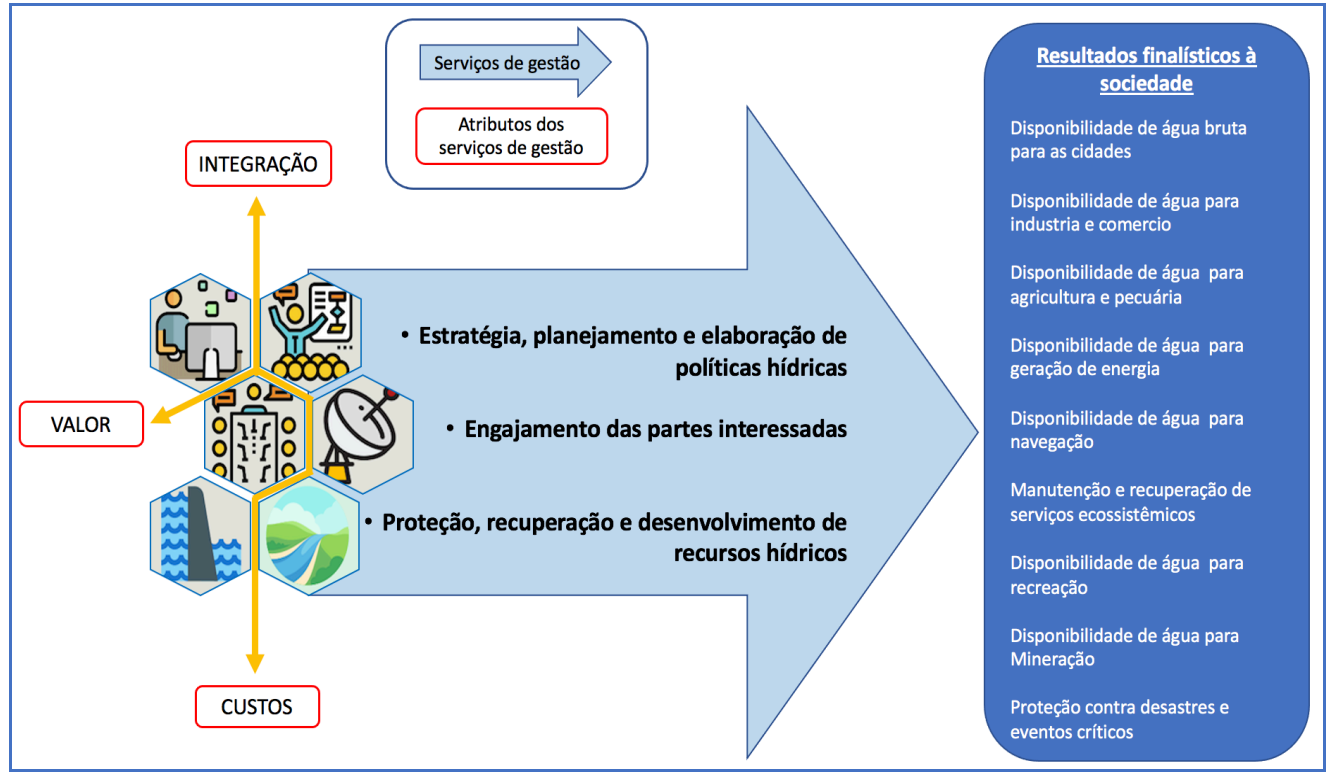

Figura 1 - Serviços de gestão de recursos hídricos, seus atributos e os resultados finalísticos para a sociedade.

Para que as funções de "governança e gestão de recursos hídricos" em Rees et al. (2008) se tornem efetivamente os Serviços de Gestão aqui definidos é necessário que estejam imbuídas de três atributos fundamentais, em destaque na Figura 1: integração, valor e custos. 0 primeiro atributo é que serviços têm uma visão integradora. Enquanto uma ação ou atividade existe de forma isolada, um serviço pressupõe uma série de ações coerentes e coordenadas na direção de um objetivo comum. Nesse sentido, os três grupos de ações de governança apresentados precisam se desenvolver de forma integrada para que os mesmos se tornem serviços de gestão e consigam atingir os resultados finalísticos à sociedade.

0 segundo é que serviços devem necessariamente agregar valor. Se prestados de forma efetiva, os serviços de gestão irão impactar positivamente toda a cadeia produtiva de um estado, uma bacia hidrográfica ou um país, além de aumentar a segurança dos seus cidadãos e do seu patrimônio.

0 terceiro é que os serviços têm custos, que dependem de todo o conjunto de ações compartilhadas entre os três grupos apresentados. Por essa razão, se faltam recursos para uma determinada ação importante, o impacto vai além da própria ação, comprometendo os serviços como um todo.

Por outro lado, se as atividades de governança são percebidas como serviços de gestão, quem então presta estes serviços? A resposta é: todos os atores engajados no SINGREH (e até fora do mesmo) que, com algum nível de atribuição ou responsabilidade, contribuem para os resultados finalísticos à direita no Quadro 1. Isso inclui órgãos deliberativos, formuladores e fiscalizadores de políticas (comitês de bacia, conselhos estaduais e nacional de recursos hídricos, Secretaria de Recursos Hídricos), órgão executivos de políticas e de apoio técnico-executivo (Agência Nacional de Águas, órgãos gestores estaduais, entidades delegatárias ou equiparadas de agências de água), órgãos de planejamento na área de meio ambiente e infraestrutura. Entretanto, o ente só atua na prestação do serviço se agregar ao mesmo os três atributos apresentados: integração, valor, manutenção dos custos que ao mesmo competem. Caso contrário, o ente do sistema está apenas desenvolvendo uma ação de governança isolada, sem garantia de que a mesma irá produzir resultados finalísticos à sociedade.

Para ilustrar a importância destes atributos que definem um serviço de gestão, podemos citar o "engajamento das partes interessadas". Se feito de forma isolada, é apenas uma atividade de gestão, muitas vezes com um fim em si mesma. No entanto, se o "engajamento das partes interessadas" for desenvolvido com os atributos apresentados, a sua condução deverá:

i. Construir uma percepção comum dos problemas hídricos, das relações entre os usuários e os trade-offs entre os seus usos;

ii. Utilizar a percepção em (a) para formular as políticas hídricas;

iii. Utilizar as políticas hídricas como referência para a pactuação sobre as ações a ser implementadas (ex: projetos de infraestrutura), onde e quando, de forma mais robusta e legítima. 
Percebe-se que nesse último caso o engajamento é visto como uma sequência de atividades que convergem para um resultado finalístico (por exemplo, "disponibilidade de água bruta para a cidade" (na caixa à direita no diagrama da Figura 2). Nesta lógica, o engajamento foi parte de um serviço de gestão prestado, pois (a) trouxe uma visão integrada de atividades distribuídas em todos os grupos apresentados; (b) agregou valor, na medida em que contribuiu para a escolha da solução associada aos reais problemas hídricos e (c) garantiu os recursos necessários para todos os custos ao longo do processo, assegurando o alcance do resultado finalístico.

Na lógica deste exemplo, a participação de um integrante de um comitê de bacias em uma reunião plenária faz parte da prestação de um serviço de gestão. No entanto, se os integrantes do comitê e seu grupo não estiverem capacitados para levar as questões dos seus grupos representados às plenárias, ou ainda trazer para os grupos o resultado do que foi discutido, os mesmos não estarão tomando parte na prestação do serviço, o que torna o seu engajamento uma ação isolada e com limitado potencial de impactar o resultado final. A capacitação dos comitês de bacia é hoje um desafio no Brasil, como apontado em Organização para a Cooperação e Desenvolvimento Econômico (2015) e Banco Mundial (2018a), porém, exemplos como o Programa Nacional de Fortalecimento dos Comitês de Bacias Hidrográficas Procomites (Brasil, 2016), mostram que já existem iniciativas nessa direção. Ao tratar o Engajamento do Usuário dentro da lógica proposta, percebemos que assegurar o financiamento de iniciativas como o Procomitês é uma condição necessária para a prestação do serviço de gestão.

\section{SERVIÇOS DE GESTÃO - ESTRUTURA DE CUSTOS}

Os serviços de gestão dependem de estruturas de custo específicas e gerais, que podem ser organizadas por setores, como o aqui proposto:

- Infraestrutura hídrica e projetos de recuperação (exemplos: projeto, construção, operação, manutenção e segurança);

- Infraestrutura de dados (exemplos: planejamento para a aquisição, operação e manutenção de redes de monitoramento hidrológico e meteorológico, tecnologia da informação e sistemas de processamento de dados e cadastro de usuários);

- Fiscalização (exemplos: estrutura de capital, custeio e pessoal);

- Apoio a órgãos colegiados e usuários (exemplos: capacitação, custeio de participação pública, comunicação e estrutura administrativa básica); e

- Administração e suporte técnico para tomada de decisão (exemplos: preparo de termos de referência, elaboração de planos, estudos e projetos, análise técnica e tomada de decisão, diagnósticos, comunicação, gestão de projetos e financeira, capacitação e treinamento de gestores e administração de patrimônio e recursos humanos).

Cada estrutura de custo é um elo importante no encadeamento de ações dentro dos serviços de gestão, os quais, ao mesmo tempo, compartilham estruturas de custo similares. Uma vez que o seu não atendimento leva ao comprometimento de um ou mais serviços, cabe ressaltar dois aspectos relevantes ao planejamento. 0 primeiro é a priorização dessas estruturas para o financiamento. 0 segundo é que este aspecto é também uma oportunidade para distribuir e compartilhar os custos entre fontes de recursos diferentes, tornando o seu financiamento mais robusto. Entretanto, a efetivação deste último aspecto depende da visão integradora da gestão enquanto serviço prestado. Dentre as estruturas de custo associadas aos serviços de gestão na Figura 2 "Administração e suporte técnico" e o "Apoio aos órgãos colegiados" destacam-se por compartilhar o maior número de estruturas de custo.

A partir da estrutura de custos exemplificada, a próxima pergunta é: como estes serviços são pagos? Atualmente, os canais de financiamento incluem fontes internas e externas à governabilidade do setor de recursos hídricos, incluindo parte de estrutura de custo e orçamento de entes do SINGREH e fora dele (que tem origem em Leis Orçamentárias), instrumentos como a CFURH ${ }^{1}$ que abastecem Fundos Estaduais de Recursos Hídricos, demais taxas, tarifas e preços públicos (a exemplo da cobrança pelo uso da água), além de financiamentos onerosos e doações feitas por órgãos externos. Como ainda não temos a percepção das ações de governança como serviços de gestão integradores, torna-se difícil a elaboração de um planejamento financeiro integrado capaz de dar sustentabilidade para a gestão, como recomendado em Marques et al. (2018). Neste aspecto, é importante que o desenho e

${ }^{1}$ A Compensação Financeira pela Utilização de Recursos Hídricos para Geração de Energia Elétrica (CFURH), estabelecida no § 1ํo do art. 20 da Constituição Federal, é devida pelos concessionários de geração de energia hidrelétrica e, conforme disposto na Lei no 9.648/1998, na Lei no 9.984/2000 e na Lei no 13.360/2016. Esses recursos correspondem à 7,0\% do valor da energia gerada, sendo $0,75 \%$ destinados à Agência Nacional de Águas (ANA), e 6,25\% distribuídos entre estados, municípios, FNDTC, MMA e MME. 
aprimoramento de soluções para os gargalos financeiros atuais seja pensado dentro de uma lógica de planejamento financeiro integrado transparente, que tenha serviços de gestão como fio condutor. Caso contrário, poderão tanto restar lacunas de financiamento, quanto questionamentos por parte dos usuários (ex: "eu já não pago por isso"?).

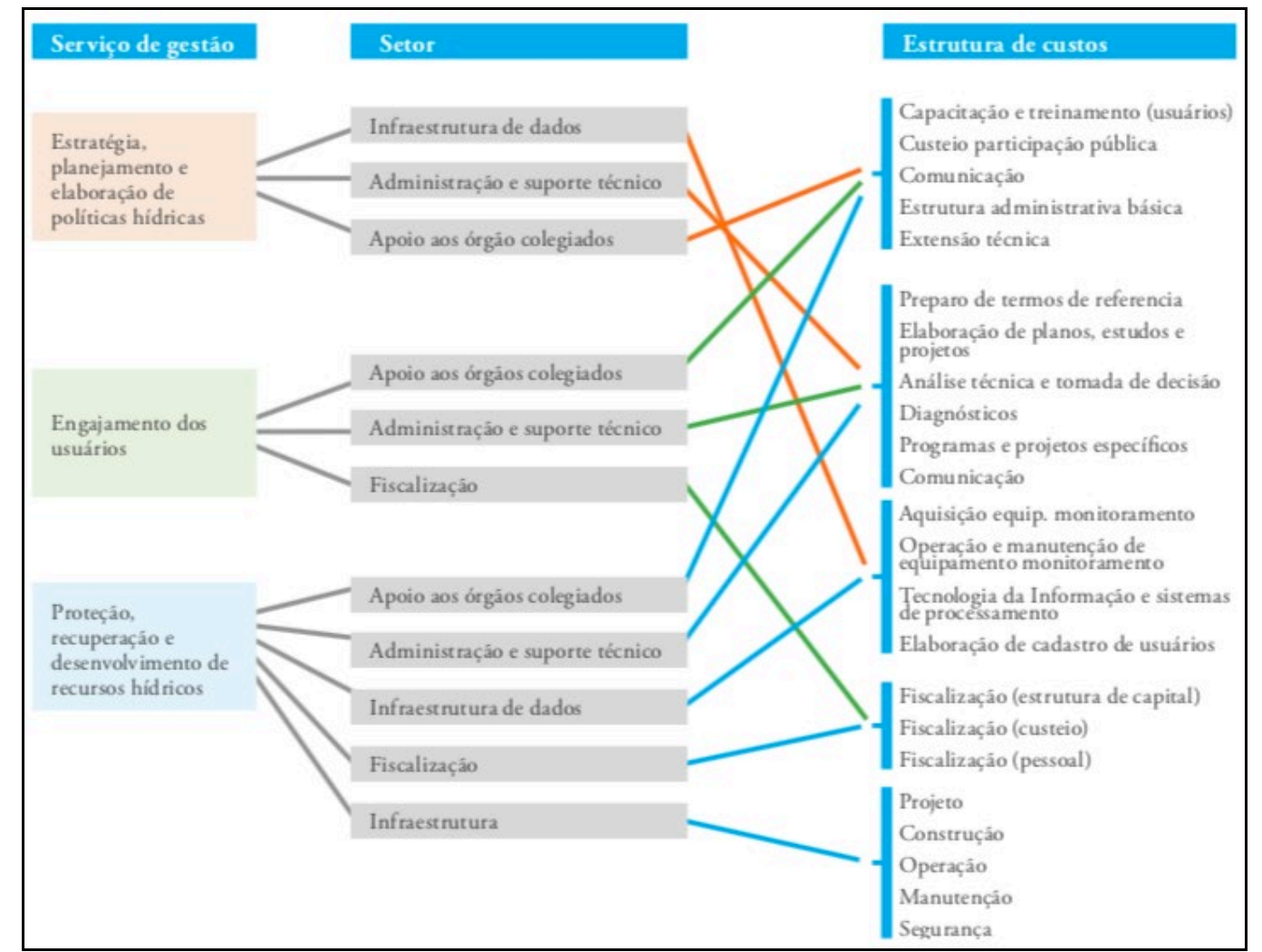

Figura 2 - Estrutura de custos por setores necessários para a prestação de serviços de gestão de recursos hídricos. Fonte: Marques et al. (2018)

\section{SERVIÇOS DE GESTÃO E SUA RELAÇÃO COM INSTRUMENTOS DA PNRH}

Os instrumentos de gestão previstos na Lei 9.433 não são equivalentes a serviços de gestão, mas constituem ferramentas que dão concretude aos mesmos. Na medida em que os instrumentos de gestão interagem diretamente com o usuário, a sua rotina e decisões, a implementação dos instrumentos pelo órgão gestor materializa a prestação dos serviços de gestão, os quais, combinados, devem entregar ao usuário o que este precisa: água bruta em quantidade, qualidade e confiabilidade requeridas para aquele determinado uso.

Fazendo um paralelo com a construção civil, é como se o serviço prestado (serviço de gestão) fosse a construção de uma casa. 0 objetivo finalístico desse serviço não é a casa em si, mas a proteção que a mesma disponibiliza ao usuário, dentre outros objetivos. Esse serviço se relaciona a vários outros (serviço de projetar, serviço de orientar e engajar o cliente para entender o que o mesmo deseja com a casa, serviço de avaliação e medições no terreno). Por fim, para concretizar a construção da casa, são necessárias ferramentas diversas: uma planilha de orçamento, uma betoneira para misturar concreto, uma trena, etc.

Em serviços como este, a estrutura de custo é cuidadosamente organizada e não se admite, por exemplo, que faltem recursos para medições no terreno (ex: topografia) caso contrário não estarão disponíveis informações críticas para o projeto. Sem o serviço de medições, não é possível prestar o serviço de construção da casa, embora seja possível executar outras ações como conversar com o cliente, decidir sobre o padrão de acabamento, etc. Entretanto, a realização destas últimas atividades sem o serviço de medições não irá garantir que a casa seja construída. Da mesma forma, a falta de ferramentas é um sério limitador para a prestação do serviço. Sem uma planilha de orçamentos (sistema de informações) a quantidade de materiais alocada pode ser superior ao permitido pelo orçamento (super alocação) e sem uma trena não há como saber se o espaço total disponível será corretamente alocado entre os cômodos que cumprem funções diferentes. Neste caso o serviço de 
construção da casa irá produzir um resultado final que dificilmente atenderá às necessidades do usuário. Finalmente, sem o conceito aglutinador e norteador do serviço que está sendo prestado, o operário não saberá o que fazer com as ferramentas.

Retomando o exemplo em recursos hídricos, para ter acesso à água bruta no rio, o usuário irá precisar do serviço de gestão Estratégia, Planejamento e Elaboração de Políticas Hídricas para registrar os usos existentes naquele corpo d'água, quantificar a disponibilidade hídrica e identificar como alocar a água entre os usos. 0 usuário irá também precisar do serviço de Engajamento das Partes Interessadas para poder interagir com os demais usuários e contribuir para a identificação dos problemas da bacia e para a deliberação sobre objetivos comuns. Finalmente, o usuário pode ainda precisar dos serviços de Proteção, Recuperação e Desenvolvimento de Recursos Hídricos para assegurar que a água disponível possa ter a sua confiabilidade aumentada via obras de infraestrutura que não sejam comprometidas por impactos ambientais.

A seguir, evidenciamos como instrumentos de gestão se relacionam com os diferentes conceitos apresentados neste artigo, sob a lógica dos serviços de gestão, por meio dos exemplos da outorga, planos, sistemas de informação e enquadramento.

\section{OUTORGA}

Embora seja possível elaborar uma Estratégia, Planejamento e Política Hídrica enquanto atividade isolada de gestão, as mesmas só serão realmente serviços de gestão prestados se contarem com alguma ferramenta para alocar a água de modo a garantir aos usuários que a disponibilidade esteja resguardada de variações hidrológicas e também dos usos dos demais usuários. Por sua vez, tanto a prestação do serviço de gestão quanto a implementação do instrumento dependem de uma estrutura organizada de recursos financeiros para existir. Para implementar o instrumento outorga são necessários recursos para custear a Infraestrutura de Dados (que tem custos com monitoramento, realização de cadastros de usuários e elaboração de sistemas de processamento da informação); Infraestrutura de Fiscalização (para monitorar a bacia) e infraestrutura de Administração e Suporte Técnico (que tem custos que envolvem toda a estrutura administrativa e o pessoal técnico que irá analisar o pedido de outorga e emitir um parecer até os custos de publicação da portaria). Se alguma dessas estruturas de custo sofrer deficiência no seu financiamento, a efetividade do instrumento outorga fica comprometida e os serviços de gestão deixam de ser prestados (uma outorga sem o adequado custeio dos elementos apresentados é apenas uma folha de papel). Neste exemplo, os envolvidos na prestação do serviço incluem órgãos gestores (que operacionalizam a outorga, organizando as informações necessárias como cadastro de usuários e fiscalizam o seu cumprimento) e comitês de bacia (que definem critérios para a outorga).

\section{PLANO DE RECURSOS HÍDRICOS (E DE BACIA HIDROGRÁFICA)}

Já a elaboração da Estratégia e Planejamento para a bacia, bem como as Políticas Hídricas, passando pela pactuação sobre quais soluções para o Desenvolvimento e Proteção dos Recursos Hídricos precisam estar materializados em um documento orientativo, que reflete o Engajamento das partes interessadas (todos estes serviços de gestão) no processo. Dessa forma, o Plano de Recursos Hídricos é o instrumento que dá concretude aos serviços de gestão elencados e o processo de planejamento (que é mais importante que o plano em si) é a própria prestação dos serviços de gestão. Assim como na outorga, tanto o serviço quanto a implementação do instrumento dependem de uma estrutura de custos, porém bem mais extensa.

Por exemplo, a elaboração de um bom Plano depende de todo um processo técnico que irá nortear desde o preparo do termo de referência até a condução da licitação e acompanhamento da entrega dos produtos. O serviço de gestão Estratégia e Planejamento é necessário para assegurar esse suporte, definindo de forma clara como deve ser o Plano em vista do contexto e demandas da bacia e quais as estratégias de engajamento e comunicação para assegurar a participação dos usuários. Em Santos et al. (2020) a avaliação do Plano de Bacias do Alto Tietê identificou a ausência de estratégias de mobilização para envolvimento do público, baixo desempenho na articulação com outras políticas e planos setoriais e generalização do escopo, com informações de pouca relevância para a identificação dos principais conflitos e em escala consideradas inadequadas pelos autores. Ao identificar recomendações para estas e outras deficiências dos Planos com mecanismos de acompanhamento e monitoramento orientados a resultados, pactos para sua implementação, mecanismos de articulação institucional e apropriação por parte de órgãos gestores, além de instrumentos e mecanismos para 
torná-los vinculantes, Persechini et al. (2018) deixam claro que os planos não têm exercido em sua plenitude a função norteadora prevista na PNRH.

Se a ausência dos instrumentos torna os serviços de gestão apenas uma promessa (sem ferramentas não se constrói uma casa), a falta do serviço de gestão resulta em instrumentos isolados, sem referência e com efetividade limitada. A efetividade dos instrumentos de gestão tem sido um grande gargalo amplamente debatido no Brasil (Organização para a Cooperação e Desenvolvimento Econômico, 2015) de modo que a adoção da visão integradora da gestão como um serviço, como proposto neste artigo, é uma forma de nortear o desenho dos instrumentos no país, definindo um fio condutor para a sua implementação e criando oportunidade para a implementação de recomendações como em Persechini et al. (2018). Os entes envolvidos na prestação destes serviços incluem órgãos gestores, entidades delegatárias ou equiparadas de agências de água, comitês de bacia e conselhos de recursos hídricos.

\section{COBRANÇA PELO USO DA ÁGUA BRUTA}

Para garantir a melhoria contínua no atendimento às demandas atuais e futuras, é necessário que os usuários façam uso racional da água (cada $\mathrm{m}^{3}$ economizado é $\mathrm{um}^{3}$ adicional disponível aos usos futuros ou atuais, em bacias com escassez hídrica severa) e que todo um conjunto de ações, programas e projetos seja implementado na bacia para resguardar e melhorar a disponibilidade. Embora este conjunto de ações seja definido e pactuado no Plano de Bacia, a cobrança, enquanto instrumento integrado ao Plano, tem o potencial de alavancar recursos para o financiamento de algumas ações e criar um ambiente incitativo ao uso racional pelos usuários (Organização para a Cooperação e Desenvolvimento Econômico, 2015; Banco Mundial, 2018a; Marques et al., 2018; Agência Nacional de Águas, 2019; Formiga-Johnsson et al., 2021; Laigneau et al., 2021; Marques et al., 2021). Nesse contexto, cabe à cobrança enquanto instrumento a função de ajudar na concretização dos serviços de gestão associados ao Engajamento das partes interessadas (na medida em que estes percebem o benefício das ações e investimentos na bacia e participam na deliberação sobre quais ações serão financiadas), Proteção, Recuperação e Desenvolvimento de Recursos Hídricos (na medida em que contribui para alavancar recursos financeiros) e Estratégia e Planejamento (na medida em que os critérios adotados pelo modelo de cobrança: de quem cobrar, onde e quanto definem também a estratégia de alocação da água, dos custos e benefícios na bacia). De modo análogo à outorga, os entes envolvidos na prestação destes serviços incluem órgãos gestores, entidades delegatárias ou equiparadas de agências de água, comitês de bacia e conselhos de recursos hídricos.

\section{SISTEMA DE INFORMAÇÕES}

No Brasil, a estrutura de custos para diversos instrumentos é fortemente compartilhada (ex: realização de cadastro de usuários, monitoramento hidrológico, fiscalização, análise técnica e tomada de decisão) o que remete a um outro instrumento importante: O Sistema de Informações. Este instrumento irá permitir que todo o processo decisório dentro do serviço de Estratégia e Planejamento seja feito a partir de fatos e dados confiáveis e disponíveis no formato e tempo certo. De modo análogo, decisões e projetos dentro de Proteção, Recuperação e Desenvolvimento de Recursos Hídricos também dependem do sistema de informações para que as soluções sejam otimizadas. Sem dados hidrometerológicos confiáveis, a incerteza aumenta e projetos se tornam mais caros e sob maior risco. Os entes envolvidos na prestação deste serviço incluem desde órgãos gestores que constroem e operam os bancos de dados, até os demais entes responsáveis pela operação e manutenção da rede hidrometeorológica de dados. A atuação da Agência Nacional de Águas na configuração da Rede Hidrometeorológica Nacional (RHN), a contribuição da CPRM na operação e até a atuação de entes privados na coleta de dados (ex: empresas geradoras de energia) são alguns exemplos.

Finalmente, o sistema de informações deve consolidar o referencial de dados sobre a bacia, que é fundamental para que os usuários construam uma visão comum sobre os problemas e a realidade da mesma e torne o Engajamento das partes interessadas possível. Em bacias com problemas de conflito pelo uso da água, iniciativas dos usuários, a exemplo do Grupo Gestor de Vazão do Alto Rio das Velhas (Ribeiro et al., 2018) buscaram monitorar e estabelecer mecanismos de controle das vazões, convergindo para um pacto entre os usuários sobre a operação do sistema (ex: liberação de vazões em reservatórios). Sem um sistema de informações acessível e confiável, engajamentos como esse 
tornam-se de difícil implementação. Os principais entes envolvidos neste serviço são os organismos de bacia, associações gestoras de açudes e outros órgãos deliberativos.

\section{ENQUADRAMENTO DOS CORPOS D'ÁGUA}

0 enquadramento dos corpos d'água materializa o serviço de Engajamento das partes interessadas (que deve envolver a sua participação para pactuar sobre os usos da água desejados), o serviço de Estratégia e Planejamento (que deve dar suporte técnico aos usuários na decisão sobre os projetos para alcançar a qualidade desejada no horizonte previsto, de forma coerente e integrada com as demais intervenções e ações na bacia, além de identificar os recursos necessários) e finalmente o serviço de Proteção, Recuperação e Desenvolvimento de Recursos Hídricos (que vai projetar e implementar as intervenções necessárias).

Como ressaltado em Agência Nacional de Águas (2013), a implementação do instrumento enquadramento depende do estabelecimento de metas realistas, análise da relação custo-benefício, seleção dos parâmetros mais adequados para refletir os problemas e vocação da bacia e a progressividade das ações. Tais aspectos demandam um grande nível de integração no planejamento, incluindo recursos hídricos, meio ambiente, saneamento e uso do solo. Em uma avaliação recente sobre o processo de enquadramento no Brasil, Machado et al. (2019) destacam um acomodamento na elaboração de diagnósticos, cenários e na definição de parâmetros-base, bem como a necessidade de programas de efetivação com acompanhamento de ações para comprovação da sua evolução. Estas lacunas envolvem ações que extrapolam o ambiente e contexto do próprio enquadramento, incluindo, por exemplo, monitoramento de qualidade da água e diagnóstico da bacia com definição de estratégias de uso e seus trade-offs, que já precisam já estar em curso para dar suporte ao enquadramento. Assim como no Plano de Bacia, a integração com outros planejamentos e a definição dos critérios necessárijos ao instrumento enquadramento pressupõe um contexto norteador. A percepção da gestão de recursos hídricos como um conjunto de serviços prestados é uma forma de criar este contexto, reforçando a ideia aos usuários e gestores de que o instrumento apenas será efetivo se for implementado dentro de uma lógica orientada a resultado (prestação de um serviço) mesmo que diversas das ações necessárias estejam fora do seu escopo de atuação e responsabilidade.

\section{A RELAÇÃO DOS SERVIÇOS DE GESTÃO COM OUTROS SERVIÇOS ASSOCIADOS À ÁGUA}

A disponibilidade de água, dentre os demais resultados finalísticos, envolve, além dos serviços de gestão, diversos outros serviços com distintas escalas geográficas de atuação. Estas diferenças no recorte geográfico resultam em relações de dependência entre os serviços, que precisam ser observadas, tanto para evitar que limitações na prestação de um serviço comprometa os demais, quando para identificar oportunidades de gestão integrada, coordenando os diferentes serviços em prol de um objetivo comum. Para explorar este aspecto, são considerados aqui dois outros serviços fundamentais, selecionados devido à presença da água como elemento importante: os serviços ecossistêmicos e os serviços de saneamento.

Para que um usuário tenha acesso à água na torneira da sua casa, serviços ecossistêmicos, de gestão e de saneamento devem funcionar. Constanza et al. (2017) define os ecossistemas que fornecem os serviços como "capital natural" (capital = estoque + fluxos), de modo que a realização de benefícios aos usuários (ex: econômicos) depende da interação deste capital natural com outras formas de capital (ex: manufaturado ou construído). Em uma bacia hidrográfica, temos um capital natural, que inclui os processos hidrológicos, geológicos e bióticos que ocorrem naturalmente, responsáveis pelo armazenamento e fluxos de água com uma determinada qualidade. Aqui, o capital natural (bacia hidrográfica, atmosfera, unidades geológicas) é quem fornece o serviço ecossistêmico.

Já os serviços de saneamento captam, tratam, armazenam e distribuem a água para os usuários, cuidando também da coleta e tratamento de efluentes e dos componentes de drenagem e resíduos. Enquanto os serviços de saneamento, cuja área de abrangência é do município, normalmente observam o escopo geográfico do mesmo, os serviços de gestão e ecossistêmicos têm como escopo toda a bacia hidrográfica (Figura 3), o que inclui municípios e áreas urbanas e rurais, ou ainda sistema hídrico interligado em casos de transposição de bacias. A sobreposição de escopos geográficos entre os três serviços considerados requer assim estratégias conjuntas e integradas para a tomada de decisão e investimentos, a exemplo daquelas analisadas em Dalcin \& Marques (2020) e Grangeiro et al. (2020). 


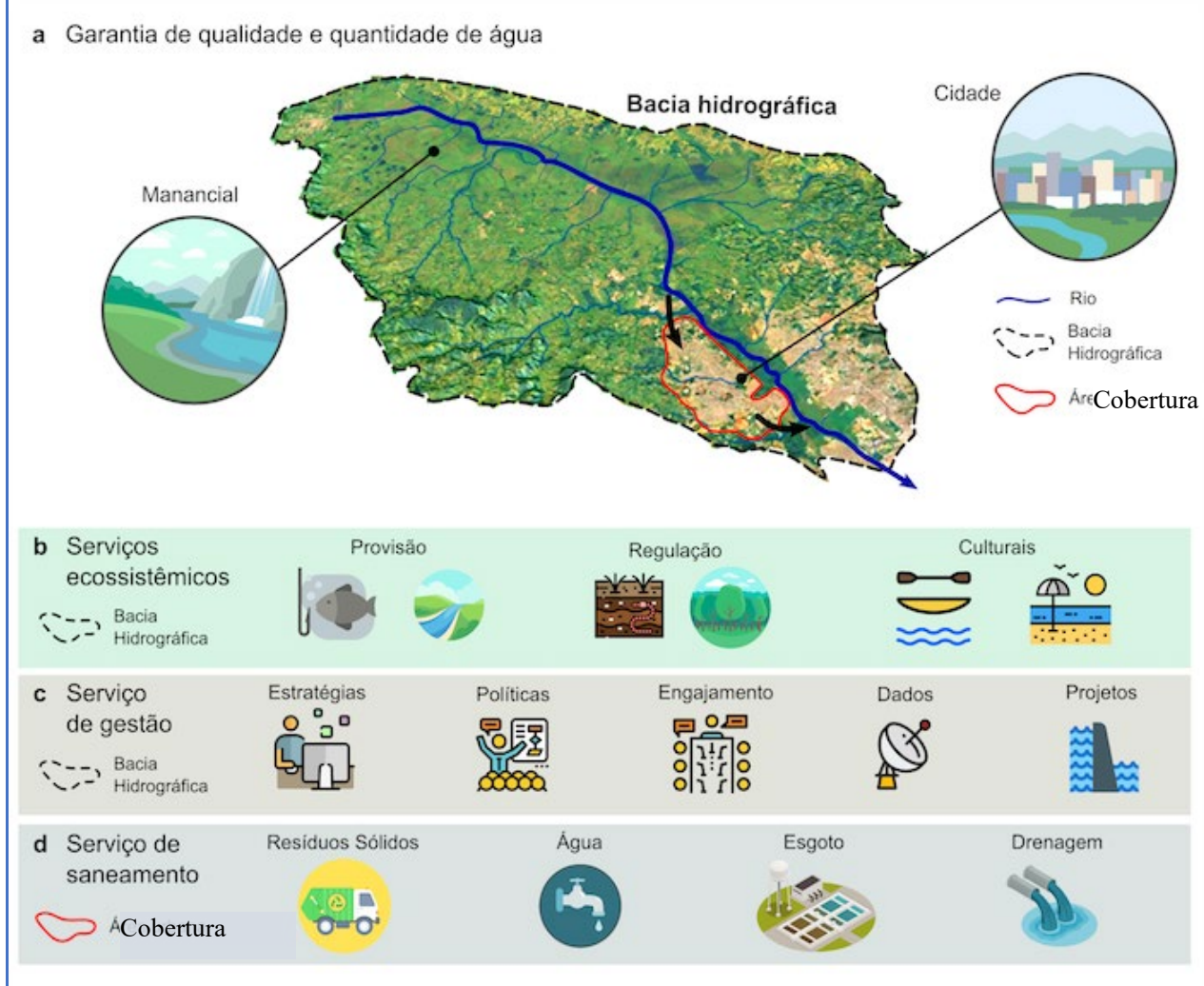

Figura 3 - Escopo geográfico dos serviços ecossistêmicos, serviços de gestão e serviços de saneamento necessários para garantir a qualidade e quantidade de água à sociedade.

Para que uma empresa de saneamento possa prestar os respectivos serviços e transformar em resultados os investimentos feitos, é necessário que a água bruta esteja disponível no rio com um nível mínimo de confiabilidade em termos qualidade e quantidade. Esta disponibilidade depende dos serviços ecossistêmicos e também dos serviços de gestão. Estes últimos irão, por exemplo: (i) definir a estratégia de proteção do solo e da água na bacia, (ii) pesquisar e coletar dados, (iii) conscientizar e informar a população, (iv) engajar usuários para decidir sobre regras de uso que afetam o balanço hídrico na bacia e (v) decidir quais intervenções e obras devem ser construídas tanto para recuperação ambiental quanto para melhoria na capacidade de armazenamento ou regularização. Cada uma dessas ações faz parte de um dos serviços de gestão definidos no diagrama da figura 2.

Quando estes serviços não são prestados, a piora na qualidade da água é um dos resultados que pode comprometer infraestruturas e investimentos já feitos pelo saneamento. Kalin et al. (2019) destacam a perda prematura de valor ou depreciação de elementos de infraestrutura hídrica (denominados stranded assets) devido à má gestão ou políticas inapropriadas.

Já os serviços de saneamento também trazem rebatimento para os próprios serviços de gestão. Sem o saneamento, a redução na qualidade da água, dentre outros impactos, compromete a disponibilidade hídrica, levando ao aumento da escassez e de conflitos, como já destacado em Heller et al. (2010). Tucci (2017) e Curtarelli et al. (2018) mostraram, por meio de indicadores, como as limitações nos serviços de saneamento influenciam o ambiente das cidades e sua área de influência, com impactos na sustentabilidade hídrica urbana. Em ambientes de escassez e conflito, os serviços de gestão tornam-se mais complexos, e potencialmente mais custosos, uma vez que podem envolver desde um monitoramento e fiscalização mais intensos, até a necessidade de maior número de programas e ações para mitigar limitações na disponibilidade hídrica, a exemplo de recomendações no Paraíba do Sul em Agência Nacional de Águas (2015). Eventos como a crise hídrica no sistema Cantareira em 2014 e a subsequente obra de transposição do Paraíba do Sul para ampliar a disponibilidade de água para a macrometrópole Paulista contrastam com a impossibilidade de uso de parte das águas de mananciais diversos devido à poluição. Ao avaliar o Índice de Comprometimento de Produção Hídrica (ICPH) no Sistema Cantareira, Whately \& Cunha (2007) corroboram este contexto, mostrando que a ocupação urbana em áreas de APP nas bacias formadoras do sistema Cantareira já traz reflexos diretos para a qualidade e quantidade da água produzida, em parte devido à ausência de tratamento de efluentes domésticos. De um modo geral, a própria segurança hídrica (Melo \& Formiga-Johnsson, 2017) depende da 
integração entre os serviços de gestão/saneamento/ecossistêmicos, trazendo a visão de bacia hidrográfica para planejamento da infraestrutura, não só de saneamento, mas de recursos hídricos de um modo geral.

Finalmente, os serviços de gestão também podem impactar positivamente os serviços ecossistêmicos/hidrológicos, na medida em coordenam a elaboração de instrumentos legais e políticos, estudo, projetos e tomada de decisão sobre a implementação de programas de revitalização e proteção de mananciais. Esta relação é corroborada pelos resultados dos efeitos de projetos de revitalização riverina reunidos em Kaiser et al. (2020) e pelas conexões entre a estrutura hidrogeomorfológica (alvo de de projetos de revitalização e proteção) e os serviços ecossistêmicos apresentada em Thorp et al. (2010). No Brasil, instrumentos legais e políticos são descritos e analisados em Ferraz et al. (2019) com o objetivo de assegurar a manutenção e a provisão de serviços ecossistêmicos em sinergia com outras iniciativas. Diversos outros exemplos recentes buscam ainda soluções baseadas na natureza - SbN - (Boelee et al., 2017) que se inspiram em processos naturais para melhorar a disponibilidade e qualidade de água (United Nations, 2007; United Nations World Water Assessment Programme, 2018).

\section{SERVIÇOS DE GESTÃO E SUA RELAÇÃO COM INSTRUMENTOS DE OUTRAS POLÍTICAS PÚBLICAS}

Embora a gestão de recursos hídricos tenha na água o seu objeto principal, as condições da água em um dado local são um reflexo de decisões tomadas em setores bastante distintos, o que requer um espectro mais amplo de instrumentos, que também guardam relações semelhantes com os serviços de gestão. Um exemplo é o Pagamento por Serviços Ambientais (PSA), que tem sido fortemente desenvolvido em todo o país nas últimas décadas e, recentemente, recebeu a guarida da Política Nacional de Pagamento por Serviços Ambientais na forma da Lei No 14.119/2021, dando destaque à importância dos serviços ecossistêmicos para o ser humano e seus sistemas produtivos.

0 potencial de um PSA depende, contudo, da observância de algumas condições e recomendações, inciando pela identificaçã

dos problemas; projetos; diagnóstico; relações inter- e intra-setoriais para obtenção de informações; beneficiários, ações, monitoramento e finalmente o engajamento, comunicação e capacitação das partes interessadas para apropriação do processo. Este último é particularmente relevante uma vez que o PSA envolve as partes interessadas de forma voluntária, tanto do lado de quem presta o serviço quanto do lado de quem recebe.

No Brasil, Fidalgo et al. (2017) e Pagiola et al. (2013) apontam como desafios ao PSA questões como o planejamento, articulação do projeto, obtenção de recursos e monitoramento. Tais demandas e dificuldades tornam o sucesso do PSA dependente da sua integração com o próprio processo de planejamento e gestão de recursos hídricos na bacia. Este argumento é reforçado em Smith et al. (2006), ao apontar que, para funcionar, as regras do PSA dependem não apenas de uma organizada estrutura institucional, mas sobretudo de uma boa estrutura de governança da água para cobrir a lacuna existente entre os acordos formais para a gestão dos recursos hídricos (as regras gerais) e a forma como os contratos de PSA serão criados e executados, melhorando a cooperação e coordenação entre diferentes setores, níveis de governo e usuários.

Este é o ponto de convergência com os serviços de gestão de recursos hídricos. Assim como os demais instrumentos, o PSA tem o potencial de contribuir para materializar os serviços de Engajamento das partes interessadas (que deve tanto atrair parceiros para o financiamento quanto interessados em implementar ações em suas propriedades); o serviço de Estratégia e Planejamento (que deve definir quais os serviços ambientais mais críticos na bacia, onde e qual a sua relação com as demais ações já previstas no plano de bacias) e finalmente o serviço de Proteção, Recuperação e Desenvolvimento de Recursos Hídricos (que vai projetar e implementar tecnicamente os projetos). A consolidação das ações de governança como os serviços de gestão elencados coloca em funcionamento toda a estrutura legal, analítica, decisória, de informações e de comunicação cujo suporte é de grande valia à operacionalização do PSA e fundamental para a sua efetividade. Finalmente, um último aspecto relevante envolve o planejamento financeiro. Um programa de PSA é, ao mesmo tempo, um demandante por recursos (especialmente no início da sua implementação) e um instrumento para canalizar investimentos na bacia. Um PSA concebido como instrumento econômico para a prestação de serviços de gestão da água permite reduzir os custos de monitoramento e fiscalização, ampliar o escopo e integrar com soluções baseadas na natureza ( $\mathrm{SbN}$ ) e infraestrutura cinza já prevista nos planos de bacia, além de atrair mais stakeholders a partir estrutura de engajamento e comunicação existente quanto do ambiente incitativo estabelecido por outros 
instrumentos. Por outro lado, um PSA bem sucedido será capaz de trazer investimentos valiosos para a bacia hidrográfica, diversificando o portfólio de fontes de recursos para financiar as ações dos planos de bacia, tornando-os mais factíveis. Este último requer, na mesma linha da cobrança, que o PSA seja, desde a sua incepção, desenhado dentro de uma lógica de financiamento integrado, como aquela apresentada em Marques et al. (2018).

\section{CONCLUSÕES}

O amplo e extensivo debate sobre a efetividade da PNRH para atingir os seus objetivos, duas décadas após a aprovação da Lei federal 9.433, vem apontando caminhos e possibilidades de aperfeiçoamento como aqueles recomendados pelo estudo Diálogos, pelos estudos da OCDE, e pela própria ANA, referenciados ao longo deste artigo. Além de aprimoramentos específicos do sistema institucional e financeiro, ponderamos aqui que se faz também necessária a revisão de alguns conceitos, buscando incorporar uma perspectiva mais abrangente, integradora e acima de tudo finalística para a gestão de recursos hídricos no país.

Esta perspectiva é importante por três razões principais. A primeira é para reforçar a visão junto a gestores, usuários e sociedade de que, se o sistema de gestão de recursos hídricos não está funcionando como um todo, muito provavelmente não está funcionando de forma efetiva. Avanços isolados acabam por se perder na medida em que gargalos impedem que benefícios sejam transferidos para o todo. Por exemplo, mesmo que a estrutura para a gestão dos rios federais avance com seus instrumentos, pactuação e capacidade técnica, esta continuará a se esbarrar nas limitações dos órgãos gestores estaduais, o que pode comprometer condições de entrega de água (quantidade e qualidade) nos pontos de confluência dos rios estaduais. A segunda é que a sustentabilidade financeira do sistema de gestão de recursos hídricos depende dessa percepção abrangente, uma vez que uma lacuna de financiamento em uma única ação pode comprometer toda uma cadeia de processos e investimentos já feitos e há a necessidade de mostrar à sociedade de forma clara como a mesma está pagando pelos serviços.

Finalmente, esta visão reforça também a necessidade da busca de soluções cooperativas entre entes e instituições diferentes do sistema, quando o trabalho de um ente depende de um outro que está fora da sua esfera de responsabilidade. Neste caso, um gargalo que atinge um ente do sistema acaba por limitar o trabalho dos demais que dependem do mesmo, comprometendo todo o resultado final. A longa rede de dependências e responsabilidades que envolvem a gestão de recursos hídricos, mostrada neste artigo por meio das estruturas de custo para a gestão deixam claro os enormes desafios desta proposta.

Acreditamos que uma forma de refletir essa visão integradora é a associação das ações de governança a serviços de gestão de recursos hídricos prestados aos usuários e à sociedade: enquanto as ações de governança apresentam cadeias próprias de atividades, custos e responsabilidades, as mesmas só trarão valor como serviços prestados à sociedade se forem integradas.

Assim como para os gestores, aos usuários e à população deve estar evidente o resultado de que a água apenas chegará às torneiras se os serviços ecossistêmicos, de gestão e de saneamento, entre outros, estiverem em bom e integrado funcionamento. Esse conceito é a base para um planejamento financeiro integrado que irá melhorar a sustentabilidade financeira de todo o sistema.

As relações dos serviços de gestão com os instrumentos de gestão indicam que há uma via de mão dupla: para serem prestados, os serviços de gestão precisam de instrumentos para entregar aos usuários os resultados finalísticos. Ao mesmo tempo, os instrumentos demandam um fio condutor para ter tanto os seus recursos assegurados quanto uma estratégia de implementação para serem efetivos.

Finalmente, o conceito de serviços de gestão é aqui proposto sobretudo com o intuito de colocar foco nos produtos e resultados finais que a Gestão de Recursos Hídricos deve prestar à sociedade. Busca-se também evidenciar que a prestação do serviço depende de uma rede de ações, investimentos e responsabilidades, nem sempre claramente observados por atores do próprio Sistema de Gerenciamento de Recursos Hídricos. Se o resultado para a sociedade não é satisfatório, o serviço não está sendo prestado adequadamente, mesmo que estejamos empregando recursos e tempo em ações de governança.

\section{AGRADECIMENTOS}

Os autores agradecem as valiosas contribuições recebidas de diversos grupos de acompanhamento, análise e discussão técnica, que não apenas trouxeram valioso feedback ao amadurecimento dos conceitos mais também compartilharam a sua rica experiência profissional, 
vinda da ANA, SRHQ, IPEA, órgão gestores estaduais, associações e representantes de usuários, órgão de governo, além de equipes do Banco Mundial. Os autores agradecem também ao Eng. Iporã Possantti pela elaboração da ilustração sobre os serviços de gestão/ecossistêmicos/saneamento.

\section{REFERÊNCIAS}

Agência Nacional de Águas - ANA. (2013). Planos de recursos hídricos e enquadramento dos corpos de água. (Cadernos de Capacitação em Recursos Hídricos, Vol. 5). Brasília: ANA.

Agência Nacional de Águas - ANA. (2015). Plano de ações complementares para a gestão da crise hídrica na bacia do Rio Paraíba do Sul (Versão 2.0 de Junho de 2015).

Agência Nacional de Águas - ANA. (2017a). Conjuntura dos recursos hídricos no Brasil 2017: relatório pleno. Brasília: ANA.

Agência Nacional de Águas - ANA. (2017b). 20 propostas para aperfeiçoamento dos marcos constitucional, legal e infralegal da gestão de águas no Brasil: preparação para o 8º Fórum Mundial da Água Brasília. Brasília: ANA.

Agência Nacional de Águas - ANA. (2019). Cobrança pelo uso dos recursos hídricos. Brasília: ANA.

Agência Nacional de Águas e Saneamento Básico - ANA. (2021). Conjuntura dos recursos hídricos no Brasil 2021. Relatório pleno. Brasília: ANA.

Banco Mundial. (2018a). Diálogos para o aperfeiçoamento da Política e do Sistema de Recursos Hídricos no Brasil. Volume 1: Relatório consolidado. Brasília: Banco Mundial.

Banco Mundial. (2018b). Diálogos para o aperfeiçoamento da Política e do Sistema de Recursos Hídricos no Brasil. Volume II: Relatório consolidado (Anexos). Brasília: Banco Mundial.

Banco Mundial. (2018c). Diálogos para o aperfeiçoamento da Política e do Sistema de Recursos Hídricos no Brasil. Sumário executivo. Brasília: Banco Mundial.

Boelee, E., Janse, J., Gal, A. L., Kok, M., Alkemade, R., \& Ligvoet, W. (2017). Overcoming water challenges through nature-based solutions. Water Policy, 19(5), 820-836.

Braga, C. F. C., Oliveira, P. P. F., Molejon, C., \& Formiga-Johnsson, R. M. (2018). Diálogos para o aperfeicoamento da Política e do Sistema de Recursos Hidricos no Brasil: Tema 2: Orgãos Gestores nos Niveis Federal (ANA) $e$ Estadual (Vol. 3). Brasília: Banco Mundial.

Brasil. Agência Nacional de Águas - ANA. (2016). Resolução no 1.190 de 3 de Outubro de 2016. Documento no 00000.056032/2016-35. Aprova o Regulamento do Programa Nacional de Fortalecimento dos Comitês de Bacias Hidrográficas - PROCOMITÊS e dá outras providências. Diário Oficial [da] República Federativa do Brasil, Brasília.

Canali, G. C., Oliveira, P. P. F., Molejon, C., \& Formiga-Johnsson, R. M. (2018). Diálogos para o aperfeiçoamento da Política e do Sistema de Recursos Hídricos no Brasil: Tema 5: Aspectos dos arcabouços legal e institucional (Vol. 6). Brasília: Banco Mundial.

Constanza, R., Groot, R., Braat, L., Kubiszewski, I., Fioramonti, L., Sutton, P., Farber, S., \& Grasso, M. (2017). Twenty years of ecosystem services: how far have we come and how far do we still need to go? Ecosystem Services, 28, 1-16.

Curtarelli, M. P., Tucci, E. M., Ragghianti, V., \& Guimaraes, V. (2018). Sustentabilidade hídrica urbana: o caso de santa catarina. Revista de Gestão de Água da América Latina, 15, e13.

Dalcin, A. P., \& Marques, G. F. M. (2020). Coordination of sanitation investment decisions with broader water resources management. REGET, Santa Maria, 24, e14. Recuperado em 27 de janeiro de 2021, de https://doi.org/10.5902/2236117062686.

Ferraz, R. P. D., Prado, R. B., Parron, L. M., \& Campanha, M. M. (2019). Marco referencial em serviços ecossistêmicos. Brasília, DF: Embrapa. 160 p.

Fidalgo, E. C. C., Prado, R. B., Turetta, A. P. D., \& Schuler, A. E. (2017). Manual para pagamento por serviços ambientais hídricos: seleção de áreas e monitoramento. Brasília, DF: Embrapa.

Formiga-Johnsson, R. M., Laigneau, P., Marques, G. F., Goldenstein, S., \& Bonilha, I. (2021). Articulação entre Planos de bacia \& Cobrança pelo uso da água: reflexões e propostas a partir do caso das Bacias PCJ. In XXIV Simpósio Brasileiro de Recursos Hídricos. Belo Horizonte: SBRH.

Grangeiro, E. L. A., Pinheiro, M. M. R., \& Miranda, L. I. B. (2020). Integração de políticas públicas no Brasil: o caso dos setores de recursos hídricos, urbano e saneamento. Cadernos Metrópole, 22(48), 417-434. Recuperado em 27 de janeiro de 2021, de http://dx.doi.org/10.1590/2236-9996.2020-4804. 
Gurria, A. (2006). Enhancing access to finance for local governments financing water for agriculture: task force on financing water for all, report 1. Marseille: CME.

Hanak, E., Gray, B., Lund, J., Mitchell, D., Chapelle, C., Fahlund, A., Jessoe, K., Medellín-Azuara, Misczynski, D., Nachbaur, J., \& Suddeth, R. (2014). Paying for water in California. California: Public Policy Institute of California (PPIC).

Heller, L., Oliveira, A. P. B. V., \& Rezende, S. C. (2010). Políticas públicas de saneamento: por onde passam os conflitos?. In A. Zhouri \& K. Laschefski (Orgs.). Desenvolvimento e conflitos ambientais (pp. 302-328) Belo Horizonte: Editora UFMG.

Kaiser, N. N., Feld, C. K., \& Stoll, S. (2020). Does river restoration increase ecosystem services? Ecosystem Services, 46, 101206.

Kalin, R. M., Mwanamveka, J., Coulson, A. B., Robertson, D. J. C., Clark, H., Rathjen, J., \& Rivett, M. O. (2019). Stranded assets as a key concept to guide investment strategies for sustainable development goal 6. Water, 11, 702. Recuperado 27 de janeiro de 2021, de http://dx.doi.org/10.3390/w11040702.

Kelman, J. (2020). A transposição do São Francisco ameaçada. Recuperado em 27 de janeiro de 2021, de https://valor.globo.com/opiniao/coluna/a-transposicao-do-sao-francisco-ameacada.ghtml.

Laigneau, P., Formiga-Johnsson, R. M., Marques, G. F., Goldenstein, S., \& Bonilha, I. (2021). A experiência francesa de planejamento de bacias hidrográficas vinculada à cobrança pelo uso de recursos hídricos. In XXIV Simpósio Brasileiro de Recursos Hídricos. Belo Horizonte: SBRH.

Lanna, A. E. (1999). Texto de referência da disciplina gestão de recursos hídricos: Programa de Pós-Graduação em Recursos Hídricos e Saneamento Ambiental. Porto Alegre: IPH-UFRGS.

Machado, E. S., Knapik, H. G., \& Bitencourt, C. C. A. (2019). Considerações sobre o processo de enquadramento de corpos de água. Engenharia Sanitaria e Ambiental, 24(2), 261-269.

Marques, G. F., Freitas, P., Molejon, C., \& Formiga-Johnsson, R. M. (2018). Diálogos para o aperfeiçoamento da Política e do Sistema de Recursos Hídricos no Brasil: Tema 4: Sustentabilidade Financeira (Vol. 5). Brasília: Banco Mundial.

Marques, G. F., Laigneau, P., Formiga-Johnsson, R. M., Goldenstein, S., \& Bonilha, I. (2021). Operacionalização da articulação entre Planos de bacia \& Cobrança pelo uso da água com suporte de Ferramenta de Simulação Financeira - Aplicação Bacias PCJ. In XXIV Simpósio Brasileiro de Recursos Hídricos. Belo Horizonte: SBRH.

Matheiß, V.; Strosser, P.; \& Carrasco, J.M. (2010). Notes on financing water resources management - Background report for the OECD Expert Meeting on Water Economics and Financing. Paris, 15-17 March 2010.

Medeiros, A. C., Oliveira, P. P. F., Molejon, C., \& Formiga-Johnsson, R. M. (2018). Diálogos para o aperfeicoamento da Política e do Sistema de Recursos Hidricos no Brasil: Tema 1: Modelo de Gestão face às Realidades Hidroclimáticas (Vol. 2). Brasília: Banco Mundial.

Mehta, L., \& Canal, O. M. (2004). Financing water for all: behind the border policy convergence in water management. Brighton: Institute of Development Studies.

Melo, M. C., \& Formiga-Johnsson, R. M. (2017). 0 conceito emergente de segurança hídrica. Sustentare, Três Corações, 1(1), 72-92.

Organização para a Cooperação e Desenvolvimento Econômico - OCDE. (2015). Princípios da OCDE para a governança da água. Recuperado em 27 de janeiro de 2021, de http://www.oecd.org/env/watergovernancepro- gramme.htm.

Organização para a Cooperação e Desenvolvimento Econômico - OCDE. (2017). Cobranças pelo uso de recursos hídricos no Brasil: Caminhos a seguir. Paris: Éditions OCDE.

Organização para a Cooperação e Desenvolvimento Econômico - OCDE. (2012). A framework for financing water resources management. Paris: OECD Publishing.

Pagiola, S., Carrascosa, H. G., \& Taffarello, D. (2013). Experiências de pagamentos por serviços ambientais no Brasil. São Paulo: Secretaria do Meio Ambiente/Coordenadoria de Biodiversidade e Recursos Naturais. 336 p.

Persechini, I., Oliveira, P. P. F., Molejon, C., \& Formiga-Johnsson, R. M. (2018). Diálogos para o aperfeiçoamento da Política e do Sistema de Recursos Hídricos no Brasil: Tema 3: Planos de Recursos Hídricos em Bacias Hidrográficas (Vol. 4). Brasília: Banco Mundial.

Rees, J. A., Winpenny, J., \& Hall, A. W. (2008). Water Financing and Governance: TEC background papers, No 12. Stockholm: Global Water Partnership Technical Committee (TEC).

Ribeiro, J., Lemos, R., Cota, G., Magalhães, A., \& Peron, G. (2018). A abordagem de conflitos pelo uso da água na gestão de recursos hídricos - reflexões a partir do contexto da Bacia do Alto Rio das Velhas, MG. Caminhos de Geografia Uberlândia, 19(68), 343-361. 
Santos, S. M., Souza, M M. P., Bircol, G. A. C., \& Ueno, H. M. (2020). Planos de bacia e seus desafios: o caso da bacia hidrográfica do Alto Tietê-SP. Ambiente \& Sociedade, 23(2), 2342.

Smith, M., Groot, D., \& Bergkamp, G. (2006). Pay establishing payments for water - shed services. Gland, Switzerland: IUCN. 109 p.

Thorp, J., Flotemersch, J. E., Delong, M., Casper, A. F., Thoms, M. C., Ballantyne, F., Williams, B. S., O'Neill, B. J., \& Haase, C. S. (2010). Linking ecosystem services, rehabilitation, and river hydrogeomorphology. Bioscience, 60, 67-74. Recuperado em 27 de janeiro de 2021, de http://dx.doi.org/10.1525/bio.2010.60.1.11.

Tucci, C. E. M. (2017). Indicador de sustentabilidade hídrica urbana. Revista de Gestão de Água da América Latina, 14, e7.

United Nations - UN. (2007). Recommendations on Payments for Ecosystem Services in Integrated Water Resources Management: Economic commission for Europe. New York/Geneva: Convention on the Protection and Use of Transboundary Watercourses and International Lakes.

United Nations World Water Assessment Programme - UN-WATER. (2018). The United Nations World Water Development Report 2018: nature-based solutions for water. Paris: UNESCO. Recuperado em 27 de janeiro de 2021, de http://unesdoc.unesco.org/images/0026/002614/261424e.pdf.

Whately, M., \& Cunha, P. ( 2007). Cantareira 2006: um olhar sobre o maior manancial de água da Região Metropolitana de São Paulo. São Paulo: Instituto Socioambiental.

Winpenny, J. (2003). Financing water for all: report of the world panel on financing water infrastructure. Recuperado em 27 de janeiro de 2021, de www.worldwatercouncil.org/download/CamdessusReport.pdf

WORLD WATER COUNCIL. (2015). Water: fit to finance? Catalyzing national growth through investment in Water Security: Report of the high level panel on financing infrastructure for a water-secure world. Marseille: World Water Council.

\section{Contribuição dos autores:}

Guilherme Fernandes Marques: Concebeu a lógica, estruturou os conceitos e redigiu o artigo.

Rosa Maria Formiga-Johnsson: Estruturou a lógica, aprimorou os conceitos e revisou o artigo.

Paula Pedreira de Freitas de Oliveira: Revisou e aprimorou os conceitos, com a ênfase para a integração entre os serviços de gestão. Revisou o artigo.

Carmen Molejon: Revisou o artigo e aprimorou a relação com a estrutura de governança no Brasil.

Cybelle Frazão Costa Braga: Revisou o artigo e aprimorou os conceitos, com enfoque na relação com os instrumentos de gestão e governança. 